Industrial Administration and Economic Policy Science and the Structure of Society. By Sir Richard Gregory, F.R.S. . . . . . .

Biological Oxidations. By Dr. J. H. Quastel, F.R.S. North American Hardy Trees and Shrubs. By B. O. Mulligan . . . . . . . . Tswett's Adsorption Analysis. By Dr. R. A. Morton . . . . . . . . . 8

The Origin of Man. By Dr. R. Broom, F.R.S. . 10

A New Process for Liquefying Air. By J. H. Awbery 14

The Search for Economic Plants. By Sir Arthur W. Hill, K.C.M.G., F.R.S.

Obituaries :

Prof. F. Aveling. By A. W. Wolters . . . 17

Mrs. H. H. Brindley. By Dr. W. H. Thorpe . 17

Prof. H. Freundlich, For. Mem.R.S. . . . 18

Prof. J.W. C. Gunn. By Prof. A. J. Clark, F.R.S. 18

News and Views . . . . . . . . . . 19

Letters to the Editors :

A New Method for the Estimation of Trigonelline in Urine and Foodstuffs.-Dr. E. Kodicek, and Dr. Y. L. Wang
I

4

5

7

8
19

18

8

Sulphanilylguanidine.-Tom Dewing and Sydney Smith . . . . . . . .

Vitamin A in Canned Salmon.-Dr. T. Moore . 24

Constitution of Yohimbine.-M. J. S. Dewar and Dr. F. E. King . . . . . . . 25

Salaman's Culture of Blight Resistant 'Aya papa'. -J. G. Hawkes and H. W. Howard . . . 25

The Recombination Law for Weak Ionization. -Dr. P. J. Nolan . . . . . . . . 26

Surface Films of Polar Crystals.-Sir Joseph Larmor, F.R.S. . . . . . . . 26

Flow Properties of Some. Thermoplastics.-Dr. W. G. Wearmouth and I. I. Berenblut.

'Shot Effect' in Temperature-Limited Diodes. -M. Surdin . . . . . . . . . 27

Physical Interpretation of Quantum Mechanics. By Prof. P. A. M. Dirac, F.R.S. . . . . 28

Observations made at the Royal Observatory, Greenwich . . . . . . . . 28

Concrete in Sea Water . . . . . . 29

The Imperial Cancer Research Fund. By Dr. E. Boyland ... . . 29

\title{
INDUSTRIAL ADMINISTRATION AND ECONOMIC POLICY
}

$\mathrm{F}^{\mathrm{A}}$ more effectively than the Limitation of Supplies Orders or the policy of concentration of production already announced by the President of the Board of Trade, the rationing of clothing in Great Britain has brought home to every member of the community the importance of utilizing to the maximum advantage all our resources of moneys, materials and man- or woman-power. The contribution and co-operation of the individual citizen are essential, but our war effort may fail of its full effect if they are not directed and utilized. to the utmost by wise administration and skilful management, whether on the part of Departments of State or in industry. The significance of scientific management and sound administration can scarcely be overstressed. They affect most powerfully the morale of the general population, which in total war is of as much importance as maintaining morale in the fighting services.

There are, unfortunately, many signs that this is far from being generally realized, or at any rate invariably served, by management or administration, as recent reports of the Select Committee on National Expenditure indicate. Its recommendation that day-time manning strengths in the civil defence services should be reduced to the minimum consistent with safety was prompted largely by the importance of minimizing the detrimental effect on morale and efficiency of an unnecessarily large amount of standing-by and waiting. The severity of its censure on the Ministry of Health for failure to supply information which would permit a judgment as to whether nursing staffs in the emergency hospital service are excessive is to be attributed as much to the desire to avoid waste and damage to morale of staff kept standing by unnecessarily, while similar staff elsewhere is overstrained, as to the ineptitude and incompetent administration thus revealed.

Other disclosures of the detrimental effect of inefficient administration on economy are contained in the twelfth and fifteenth reports of the Committee. In the former, sharp comment is made on the deterrent effect, as regards suggestions for increased economy and efficiency, of the cumbrous machinery through which these suggestions have to pass before reaching a level at which decisive action can be taken. Sensible suggestions, moreever, have been turned down as a matter of routine, apparently before reaching an officer who was sufficiently informed to appreciate them. In the matter of complaints, this position leads to the 
more vigorous or influential complainants taking undesirable short cuts to overcome their personal difficulties, and it does not appear that the administration has been sufficiently wise to appreciate the way in which this state of affairs merely increases the difficulties of others, engenders friction and reduces general efficiency.

Other indictments of administrative neglect of elementary principles of scientific management are seen in the fact that valuable information can often only be acquired by direct contact with those who have to give practical effect to decisions and are usually working away from headquarters, and the Committee comments that, however effective may be the various means of collecting information, this work will be wasted unless its results are rapidly brought to the notice of those who have power to decide what modifications of practice and policy may be immediately required.

The Select Committee points cut that apart from the failure of information and eriticism to percolate from those actually carrying out the work to those who are directing and controlling it at the centre, highly placed witnesses have made statements which suggest either that they are unaware of some of the relevant facts and considerations, or that they have not fully appreciated their practical significance. It is sometimes difficult to escape the impression that they work in an atmosphere which is too strongly buffered from outside impacts. Moreover, the Committee stresses the great importance that the facts which it has readily been able to collect, but which, under war conditions, it is unable to support by full publication of the evidence taken, should have been collected, sifted and studied by responsible officers in the departments. Only in this way can recommendations for reducing waste by increasing efficiency of management be judged in their correct setting.

Whereas the disclosures in the fifteenth report are primarily those of failures of human nature, the need for effective administration is no less clearly indicated. The suggestion that idle labour was becoming a permanent and undesirable feature in the aircraft industry generally is disturbing, and all the more in the evidence of management so inept that it failed to keep the essential records which the Select Committee has now recommended should be enforced. Similarly, the recommendations that the Ministry of Labcur shculd endeavour by publicity to give women a better idea of the kind of factory work for which they are needed, that Sunday labour should be discontinued except for the maintenance and repair of plant and other essential purposes, and that the Ministry of Aircraft Production should do everything in its power to ensure that factories working for it, either commercially or on a management fee basis, observe district federation wage-rates and keep their bonus percentages in line with those of their neighbours, involve essentially reflections on the foresight, imagination and competence of the administrations concerned.

It would be unfair to suggest that the question of absenteeism, which the Select Committee finds so disturbing, is one for management alone. With so much evidence of inefficient, if not incompetent management, however, it is difficult to believe that improvement in this respect and the maintenance of a more scientific standard would not go far to reduce avoidable absenteeism to a figure when it should easily be possible to deal with recalcitrant elements in personnel. In any event, we cannot afford in war-time to tolerate ineptitude and incompetence in management. The Select Committee's reports alone afford sufficient evidence of the waste and difficulties which flow from this source.

Unquestionably these reports indicate that civil administration in Great Britain is far from attaining the standard that the country has a right to expect. The restrained criticism is a severer indictment of civil service efficiency than such violent attacks as those of Lord Percy, and it would be reassuring to learn what action has been taken upon recommendations so authoritatively prepared and objectively stated. Nor is the indictment of industrial management any less penetrating, and it is scarcely reassuring to find, in view of the shortcomings of industrial management simultaneously exposed, that leading positions in the Ministry of Supply, the Ministry of Aircraft Production, the Ministry of Food and the ministries concerned with economic reconstruction have been entrusted to representatives of industrial organiza. tions, rather than to individuals on their outstanding ability.

It is for this reason that Mr. Hugh Quigley's pamphlet in "The Democratic Order" series* is timely. He subjects the whole structure and policy of industry in relation to efficient administration and control to analysis from the point of view of serving the needs of the community-the raison d'être of industry in the ultimate analysis. Funda* End Monopoly Exploitation : a Policy for Industry.
Quigley, (The Democratic Order, No. 15.) Py. 63. (London: Kegan Paul and Co., Ltd., 1941.) 18, net. 
mentally he raises the question, not so much of industrial policy, as of the machinery of government and its adequacy under present and post-war conditions.

Mr. Quigley makes his first important point in suggesting that the present industrial order should be replaced by one in which industry is subordinate to the State, in so far as the State seeks to advance the public welfare, and in which industry does not at any point dominate the public; either through its organizations or through its methods of representation. This involves a sense of public responsibility as well as of efficient management which have not been approached even by the new types of public corporation. As Mr. Quigley points out, where such authorities as the British Broadcasting Corporation, the Central Electricity Board or the London Passenger Transport Board have failed, has been in their approach to the larger problems of public service which give the justification for their technical privileges. We can scarcely expect more of the executives of the industries bordering on coal-mining, building, iron and steel, chemicals, shipbuilding, electrical engineering, agricultural, or the distribution of foodstuffs, especially in the light of the evidence of the Select Committee on National Expenditure reports.

This judgment, however, narrows the problem to one not so much of executive ability or technical efficiency as to one of managerial responsibility and executive vision, and Mr. Quigley points out first that the character of new State enterprises such as the public utility companies tends to reflect the character of the national executive, and that accordingly some kind of division must be made between purely technical management, which is usually efficient, and the wider aspects of national policy which are expressed in such management. The nature and limitations of any organization created to obtain better results from the point of view of the public welfare are a matter for investigation and, for all his insistence on the necessity for some such development, Mr. Quigley is unconvinced that far-reaching nationalization is the remedy.

The great difficulty is that of higher control ; this has never been adequately considered by those who advocate the most thorough-going socialization. Moreover, attempts to co-ordinate economic policy are faced with the absence of any conception of what the tactics of higher control in economic matters should be. This is the real reason for the confusion existing, for example, in agricul- ture and in the marketing and distribution of food.

If we accept as basic the principle that no public utility or industry should be allowed to have a vested interest other than that involved in efficient production, a considerable amount of well-defined and well-supported technical, economic and social research will be required before we can evolve the technique and policy for the higher impartial controlling authority, which must possess not merely advisory functions, but also full executive powers. It involves, indeed, reconsideration of the whole machinery of government. It will be recalled that the Haldane Committee, which clearly envisaged this problem, while firmly rejecting a proposal to concentrate the administration or supervision of private enterprise in production under the same department concerned with the administration of nationalized services, contemplated some development of the Board of Trade in this field of production, but laid its main stress on the need for further provision in the sphere of civil government for the continuous acquisition of knowledge and the prosecution of research to furnish a proper basis for policy.

Mr. Quigley takes no pessimistic view of the capacity of democratic government to evolve the appropriate instruments to prevent in future the development of industry without regard to the needs of the community. Protection against exploitation, increasingly high standards of public service on the part of industries and public utilities and the right to call to account, as those in military or naval command are called to account, those in charge of such industries and public utilities if their administration fails to display courage, vision or disinterested statesmanship-these are no Utopian ideals. Despite all the evidence of inefficiency or negligence or disregard of public interest, there is no sign that the community is unable to throw up, either in the service of the State or of industry, those possessing administrative ability, high ideals, wide vision and unassailable integrity. The fields of thought and inquiry opened up by Mr. Quigley and by the Select Committee's reports go far beyond the structure of industry and organization of government: they embrace the whole character of our educational system and its capacity to throw up leaders. That these suggestions should be voiced, however, attests the vitality of democracy and its capacity of adjustment and development to meet the changing needs of a dynamic society. 